Article

\title{
Bruxism Influence on Volume and Interleukin-1 $\beta$ Concentration of Gingival Crevicular Fluid: A Preliminary Study
}

\author{
Kacper Nijakowski ${ }^{1, *,+}$ (D), Martyna Ortarzewska ${ }^{2, \dagger}{ }^{+}$Alicja Morawska ${ }^{2,+}{ }^{,}$Alicja Brożek ${ }^{3}$, Marcin Nowicki ${ }^{3}$, \\ Dorota Formanowicz $^{3}$ (D) and Anna Surdacka ${ }^{1}$ (D)
}

1 Department of Conservative Dentistry and Endodontics, Poznan University of Medical Sciences, 60-812 Poznan, Poland; annasurd@ump.edu.pl

2 Student's Scientific Group in Department of Conservative Dentistry and Endodontics, Poznan University of Medical Sciences, 60-812 Poznan, Poland; mortarzewska@gmail.com (M.O.); alicja.m.morawska@gmail.com (A.M.)

3 Department of Medical Chemistry and Laboratory Medicine, Poznan University of Medical Sciences, 60-806 Poznan, Poland; abrozek@ump.edu.pl (A.B.); nowickim@ump.edu.pl (M.N.); doforman@ump.edu.pl (D.F.)

* Correspondence: kacpernijakowski@ump.edu.pl

+ These authors contributed equally to this work.

\section{check for}

updates

Citation: Nijakowski, K.;

Ortarzewska, M.; Morawska, A.;

Brożek, A.; Nowicki, M.;

Formanowicz, D.; Surdacka, A.

Bruxism Influence on Volume and

Interleukin- $1 \beta$ Concentration of

Gingival Crevicular Fluid: A

Preliminary Study. Appl. Sci. 2022, 12,

2089. https://doi.org/10.3390/

app12042089

Academic Editor: Gaspare Palaia

Received: 30 January 2022

Accepted: 16 February 2022

Published: 17 February 2022

Publisher's Note: MDPI stays neutral with regard to jurisdictional claims in published maps and institutional affiliations.

Copyright: (C) 2022 by the authors. Licensee MDPI, Basel, Switzerland. This article is an open access article distributed under the terms and conditions of the Creative Commons Attribution (CC BY) license (https:// creativecommons.org/licenses/by/ $4.0 /)$.

\begin{abstract}
Bruxism is occlusal behaviour that often leads to stomatognathic system overload. Inflammatory markers in the periodontium are detectable in the gingival crevicular fluid (GCF). GCF production fluctuates due to various factors. Our study aimed to assess the effect of tooth clenching or grinding on GCF volume and proinflammatory IL-1 $\beta$ concentration in GCF. This pilot study was carried out on 20 participants aged 21 to 28 with good general health (per 10 people studied and control groups). GCF volume was measured with Periotron 8010 after absorbing for $30 \mathrm{~s}$ with PerioPaper strips. Twelve samples were collected from each patient-the buccal and lingual surfaces of teeth $16,11,24,36,31$, and 44 were included. Laboratory examination of IL- $1 \beta$ concentration was performed. In patients with pathological tooth wear, a tendency to increase GCF secretion and IL-1 $\beta$ concentration in GCF was found. GCF volumes were higher in posterior teeth, while IL-1 $\beta$ levels were higher in anterior teeth. Crevices at the molars seem to have a potential predictive value in diagnosing periodontal microinflammation in patients with probable bruxism. Due to occlusal overload, these bruxists are more prone to microinflammatory processes in the periodontium. Further studies in a broader group are required to confirm this correlation.
\end{abstract}

Keywords: bruxism; gingival crevicular fluid; interleukin 1 beta; Periotron; microinflammation; tooth wear; occlusal wear

\section{Introduction}

Gingival crevicular fluid (GCF) is physiologically produced in small amounts and its composition resembles blood serum. In a healthy state, GCF is responsible for leaching pathogens and toxic metabolites from the periodontium. However, during inflammation, the microcapillary framework enhances the secretion of fluid containing various inflammatory biomarkers [1]. The inflammatory exudate components include bacteria, damaged tissue fragments, proteins, complement system components, immune cells, immunoglobulins, and inflammatory mediators [2-4].

Among the biochemical inflammatory mediators, proinflammatory and anti-inflammatory interleukins are listed. Interleukin-1 (IL-1) is one of the proinflammatory nuclear factor- $\mathrm{kB}-$ dependent cytokines present in gingival fluid, and is responsible for acute phase response induction $[5,6]$. The beta form (IL-1 $\beta$ ), prevalent in periodontal tissues, is produced by macrophages [7]. Romano et al. [8] showed that IL-1 is the most important biomarker associated with chronic periodontitis. Interleukin- $1 \beta$ is sometimes referred to as a mediator 
of periodontal bone loss, as it stimulates the formation of osteoclasts and affects bone resorption [9]. Furthermore, the rs1143634 polymorphism in the interleukin-1 $\beta$ gene seems to associated with an elevated risk of chronic periodontitis in Caucasian and Asian ethnicities, as well as mixed populations [10].

As a correlation between gingival fluid volume and the periodontitis stage exists [11], researchers have long searched for an effective, non-invasive method of collecting and measuring the amount of fluid to estimate the intensity and predict the occurrence of periodontal disease $[2,12,13]$. Construction of the Periotron device (Oraflow Inc., New York, NY, USA) was crucial and became considered the most accurate, non-invasive method for diagnosing the intensity of periodontitis, useful in subclinical symptom detection. The latest available model—Periotron 8010 — additionally enables saliva testing [14]. The device uses the mechanism of an electric capacitor; it has an arm with two jaws that are its capacitor plates. Methylcellulose Periopaper strips (Oraflow Inc., New York, NY, USA) soaked in GCF are inserted between the jaws. The reading of the fluid volume is displayed in "Periotron units" (device units proportional to the change in capacitance of the capacitor). The result can be converted into SI units after plotting a standard curve using known fluid volumes [2].

Apart from periodontal diseases, the secretion of gingival fluid is influenced by various factors, such as medication intake, systemic diseases, hormonal status changes during the menstrual cycle [15], or treatment with orthodontic appliances [16]. Authors assumed that bruxism, repetitive activity of the masticatory muscles, may also impact this.

Depending on the circadian occurrence of the habit, awake bruxism and sleep bruxism are diagnosed [17]. During sleep, rhythmic or non-rhythmic muscular activity is observed. Night grinding episodes are independent of the patient's consciousness. Awake bruxism often takes the form of permanent occlusal contact and manifests itself in voiceless clenching of teeth. The daily form depends mainly on emotional state and can be controlled by the patient $[18,19]$. The etiopathogenesis of bruxism has not been fully elucidated, although the dominant factors leading to hypertonia are stress, anxiety, and genetic predisposition [20-22]. Other factors associated with bruxism include sleep disorders (e.g., obstructive sleep apnea), neurological (e.g., epilepsy) and endocrine disorders (e.g., hyperthyroidism), as well as gastroesophageal reflux disorder. Substances that promote bruxism include nicotine, caffeine, alcohol, and prescribed medications, such as antidepressants or antipsychotics [23]. The consequences of grinding and clenching are pathological wear of dental hard tissues, changes in the periodontium and oral mucosa, and stomatognathic system overload [24]. Moreover, young sleep bruxers potentially have higher cardiovascular risk due to the increased concentrations of inflammatory and stress markers [25]. Interestingly, phasic sleep bruxism seems to be positively correlated with snore intensity despite body position [26].

According to international consensus on the assessment of bruxism [17], the proposed grading system is as follows. Possible bruxism is based only on a positive self-report. For the diagnosis of probable bruxism, a positive clinical inspection with possible positive anamnesis is necessary. The last grade defined as definite bruxism requires confirmation by instrumental methods (such as electromyographic recordings) with the possibility of accompanying prior conditions. Experts also recommend that bruxism should not be considered as a disorder, but rather as a behaviour.

The study aimed to evaluate the effect of clenching, grinding, and occlusal overload on changes in the volume and interleukin- $1 \beta$ concentration of gingival crevicular fluid in patients with probable bruxism.

\section{Materials and Methods}

\subsection{Study Participants}

This pilot study was carried out on 10 volunteer patients diagnosed with probable bruxism ( 5 females and 5 males) and 10 controls ( 5 females and 5 males). The diagnosis of "probable bruxism" was made based on positive clinical inspections, with a positive self- 
report [27]. Initially, an anamnesis was conducted on: teeth grinding, clenching, morning masticatory muscle rigidity, limited mouth opening, chewing muscle pain, cheek biting, and previous treatment (including splint therapy and muscle relaxation exercises). Among the clinical signs of bruxism, the presence of masticatory muscle hypertrophy, indentations on the tongue or lips, linea alba on the buccal mucosa, as well as mechanical tooth wear were assessed. Furthermore, temporomandibular joint status was evaluated.

The examinations were performed between August and October 2020 in the Department of Conservative Dentistry and Endodontics, Poznan University of Medical Sciences, Poland. All participants were aged 21 to 28 and were in good general health without malocclusion. The exclusion criteria were: ages over 30 , smoking, periodontal diseases, poor oral hygiene, autoimmune diseases, diabetes, obesity, gastroesophageal reflux disease, use of medications affecting salivation (e.g., antidepressants, antipsychotics, sedatives, myorelaxants, antihistamines, and antihypertensives), any orthodontic treatment in the past, and the periovulatory phase of the menstrual cycle (between 12th and 15th day).

\subsection{Study Protocol}

In order to minimise the risk of measurement errors, the clinical examination was divided into the following parts: the first (sample collection and measurement of their volume) was performed by the first researcher and the second part (examination of bruxism symptoms, oral hygiene, and periodontium) by the second researcher; this was the same for every patient. These examiners were pre-calibrated by repeatedly practicing clinical trial procedures and techniques, as well as blinded to bruxism status.

In the next stage, fluid was collected from the gingival sulci of tooth $16,11,24,36,31$, and 44-buccal and lingual surfaces—for 12 measurement points (in the case of missing teeth, crowns, veneers, implants, or 2nd and 5th Black class fillings, an adjacent tooth from the same tooth group was used). The fluid was collected with a sterile methylcellulose Periopaper strip (Oraflow Inc., NY, New York, US), by gently inserting it into the gingival sulcus for $30 \mathrm{~s}-$ Figure 1 . The tooth was previously cleaned, isolated with cotton rolls and had its surface dried with an air syringe for $5 \mathrm{~s}$, directing the air stream opposite the gingival sulcus. The strip, soaked in liquid, was placed on the sensor of the lower capacitor plate of the previously calibrated Periotron 8010 (Oraflow Inc., New York, NY, USA). Then the determined amount of liquid was read in "Periotron units". In case of contamination, the sensor was cleaned with $70 \%$ ethyl alcohol and dried with the cotton roll.

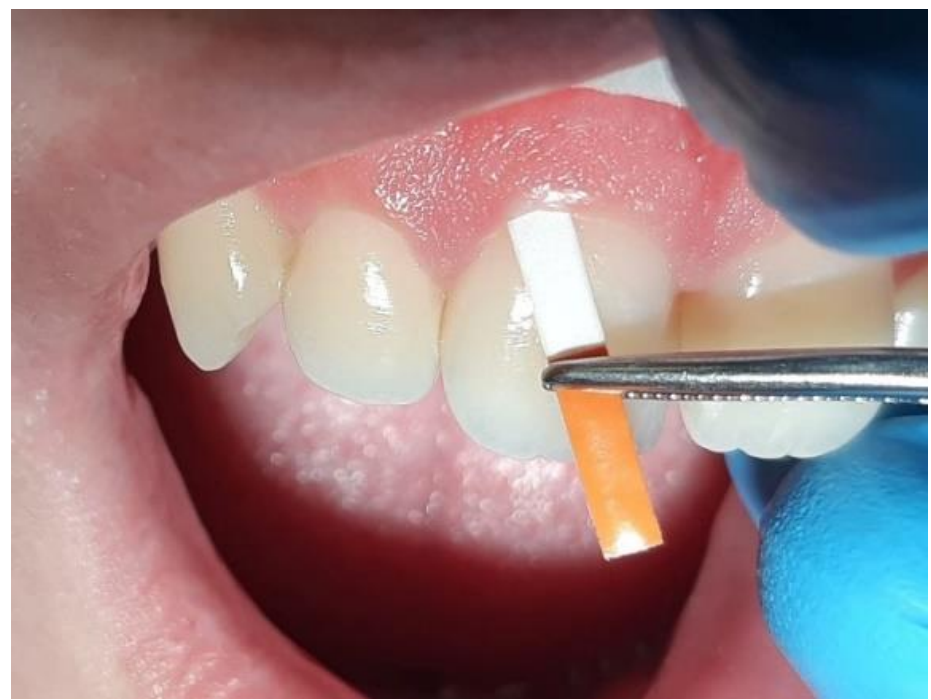

Figure 1. A Periopaper strip inserted into the gingival crevice (photo from own collection-K.N.).

A clinical examination was performed in the last stage to prevent irritating the delicate periodontal tissues with the probe or affecting the fluid volume or the occurrence of 
bleeding. We examined oral hygiene and periodontal indicators: API (approximal plaque index), SBI (sulcus bleeding index), PI (plaque index), GI (gingival index), PPD (periodontal pocket depth), as well as the TWI (tooth wear index) by Smith and Knight [28]. For TWI, a score of 0 is no enamel loss, 1 is partial enamel loss, 2 is enamel loss with dentin exposure up to $1 / 3$ of the surface, 3 is more than $1 / 3$ of the surface, and 4 is total enamel loss.

\subsection{Gingival Crevicular Fluid Samples}

The methylcellulose strip, soaked in GCF, was placed in a previously prepared tube containing $200 \mu \mathrm{L}$ of buffered saline for $30 \mathrm{~min}$. The samples had been frozen at $-80{ }^{\circ} \mathrm{C}$ until the tests were performed. The concentration of interleukin- $1 \beta$ was assessed using an appropriate diagnostic ELISA kit.

\subsection{Statistical Analysis}

Due to lack of compliance with normal distributions for both GCF volume and interleukin- $1 \beta$ concentrations, the results were presented in the box plots as medians and quartile ranges. The variables were compared using the non-parametric Mann-Whitney test. The predictive evaluation of selected variables was performed in ROC analysis.

Data were analysed using Statistica 13.3 software (StatSoft, Cracow, Poland). The significance level was set at $\alpha=0.05$.

\section{Results}

Table 1 shows the oral hygiene and periodontal status of bruxists and non-bruxists. No significant differences were found between these subgroups. Table 2 compares the degree of TWI on individual teeth in both patient groups.

Table 1. Oral hygiene and periodontal status.

\begin{tabular}{ccc}
\hline Parameter & $\begin{array}{c}\text { Bruxists } \\
\text { M [Q1-Q3] }\end{array}$ & $\begin{array}{c}\text { Non-Bruxists } \\
\text { M [Q1-Q3] }\end{array}$ \\
\hline Approximal plaque index [\%] & $23.1[16.7-26.9]$ & $15.4[10.0-23.1]$ \\
Plaque index & $0.21[0.13-0.21]$ & $0.08[0.00-0.25]$ \\
Sulcus bleeding index [\%] & $0.0[0.0-3.8]$ & $0.0[0.0-3.8]$ \\
Gingival index & $0.13[0.13-0.21]$ & $0.08[0.04-0.17]$ \\
Periodontal probing depth [mm] & $1.15[1.02-1.29]$ & $1.35[1.04-1.73]$ \\
\hline
\end{tabular}

Table 2. Comparison of the Tooth Wear Index between bruxists and non-bruxists.

\begin{tabular}{cccc}
\hline TWI & $\begin{array}{c}\text { Bruxists } \\
\text { M [Q1-Q3] }\end{array}$ & $\begin{array}{c}\text { Non-Bruxists } \\
\text { M [Q1-Q3] }\end{array}$ & $p$-Value \\
\hline 16 & $1.0[1.0-2.0]$ & $0.0[0.0-1.0]$ & $0.013^{*}$ \\
11 & $1.0[1.0-2.0]$ & $1.0[0.0-1.0]$ & 0.058 \\
24 & $1.0[1.0-2.0]$ & $0.0[0.0-0.0]$ & $0.010^{*}$ \\
36 & $1.0[1.0-2.0]$ & $1.0[0.0-1.0]$ & $0.018^{*}$ \\
31 & $2.0[1.0-2.0]$ & $1.0[1.0-2.0]$ & 0.098 \\
44 & $2.0[1.0-2.0]$ & $0.0[0.0-1.0]$ & 0.003 * \\
Total & $1.5[1.2-1.5]$ & $0.5[0.2-0.8]$ & $<0.001$ * \\
\hline
\end{tabular}

${ }^{*} p$-value $<0.05$ for the Mann-Whitney test.

Figures 2 and 3 present the results for GCF volume and interleukin- $1 \beta$ concentration. Table 3 shows also the $p$-values for comparing non-bruxists and bruxists. 


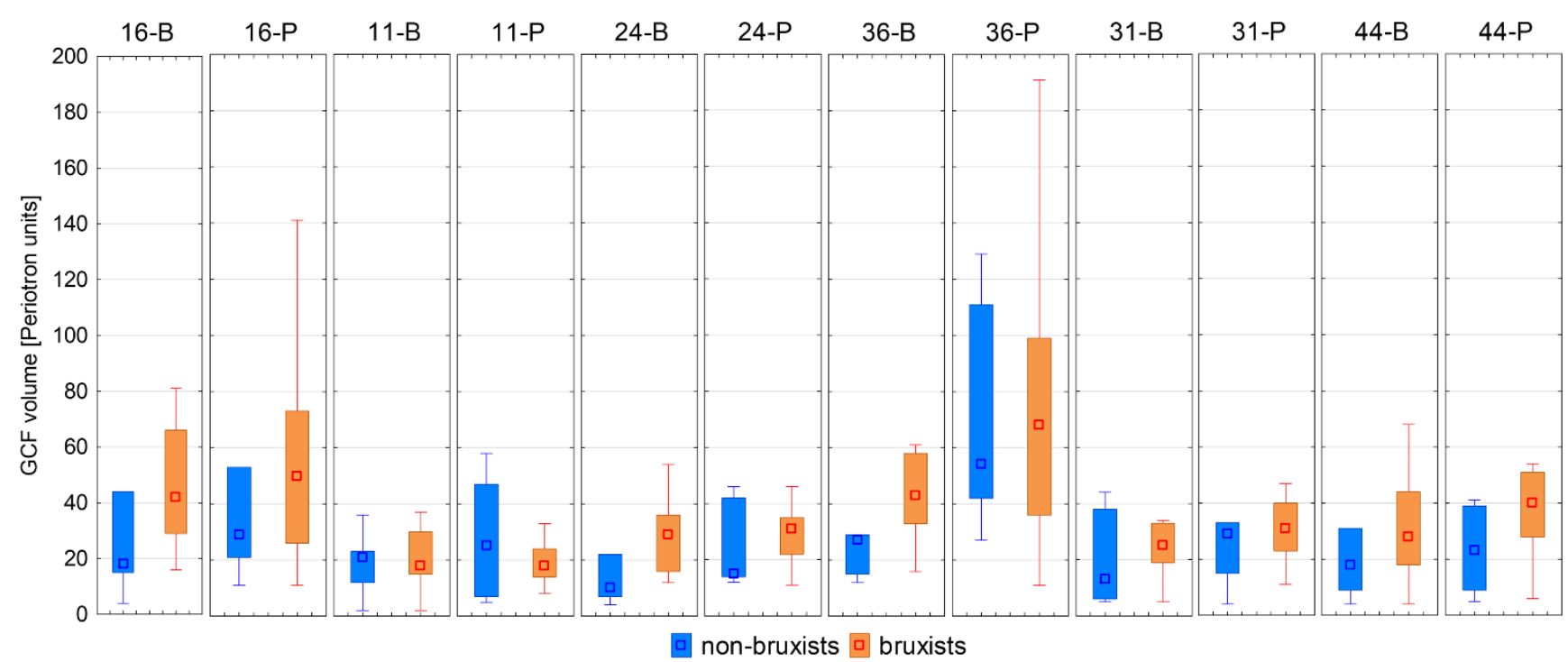

Figure 2. A comparison of gingival crevicular fluid volume in bruxists and non-bruxists-Median, Q1-Q3, Min-Max (B, buccal/labial; P, palatal/lingual).

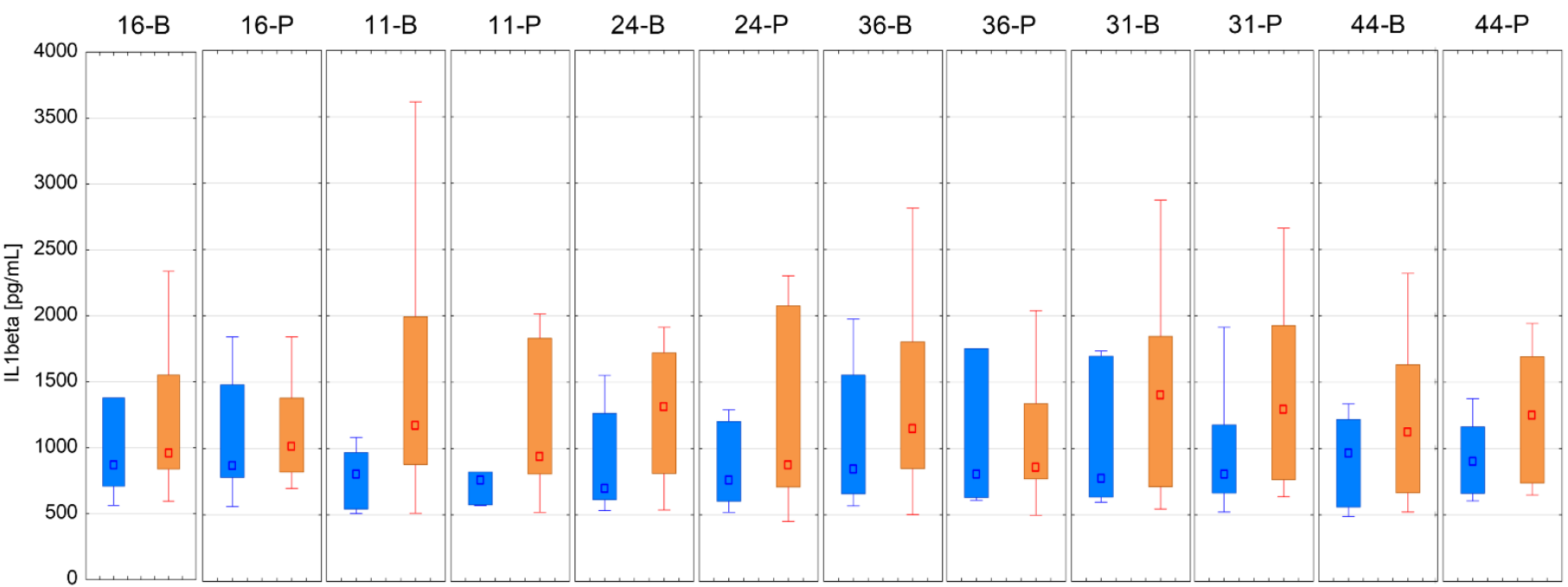

ㅁ non-bruxists $\square$ bruxists

Figure 3. A comparison of interleukin- $1 \beta$ concentration in bruxists and non-bruxists-Median, Q1-Q3, Min-Max (B, buccal/labial; P, palatal/lingual).

The lowest GCF volumes were measured for incisor teeth and the highest for molars in both groups. In patients showing signs of tooth wear, increased volumes of secreted GCF were observed for almost all pockets tested, and was particularly statistically significant for a buccal one in tooth 36. The greatest upward trend in GCF volume in bruxists was for premolars and molars.

Patients with pathological tooth wear, compared to the group without tooth wear, showed increased median concentrations of proinflammatory interleukin- $1 \beta$ in all teeth examined. The greatest increasing tendency in the bruxists concerned the crevices of incisors and premolars. A particularly statistically significant difference was obtained for the sulcus on the palatal side of tooth 11.

Additionally, ROC analyses were performed to assess the prediction of bruxism and thus periodontal microinflammation on the basis of determined parameters. Figures 4 and 5 present the ROC curves for the five most predictive gingival sulci. Detailed results are shown for the GCF volume and interleukin-1 $\beta$ concentration in Tables 4 and 5 . 
Table 3. Results comparing bruxists and non-bruxists.

\begin{tabular}{|c|c|c|c|c|c|c|}
\hline & \multicolumn{3}{|c|}{ GCF Volume [Periotron Units] } & \multicolumn{3}{|c|}{ IL-1 $\beta[\mathrm{pg} / \mathrm{mL}]$} \\
\hline & $\begin{array}{c}\text { Bruxists } \\
\text { M [Q1-Q3] }\end{array}$ & $\begin{array}{c}\text { Non-Bruxists } \\
\text { M [Q1-Q3] }\end{array}$ & $p$-Value & $\begin{array}{c}\text { Bruxists } \\
\text { M [Q1-Q3] }\end{array}$ & $\begin{array}{c}\text { Non-Bruxists } \\
\text { M [Q1-Q3] }\end{array}$ & $p$-Value \\
\hline $16-\mathrm{B}$ & $42[29-66]$ & $18[15-44]$ & 0.165 & $960.6[839.4-1551.3]$ & $870.0[708.3-1377.2]$ & 0.526 \\
\hline $16-\mathrm{P}$ & $50[26-73]$ & $29[21-53]$ & 0.405 & 1011.8 [823.7-1379.4] & $866.5[783.9-1479.4]$ & 0.663 \\
\hline $11-\mathrm{B}$ & $18[15-30]$ & $21[12-23]$ & 0.937 & 1175.6 [880.9-1993.9] & $808.9[545.7-970.2]$ & 0.062 \\
\hline 11-P & $18[14-24]$ & $25[7-47]$ & 0.382 & 937.6 [808.9-1830.2] & $758.6[575.1-823.7]$ & 0.048 * \\
\hline $24-B$ & $29[16-36]$ & $10[7-22]$ & 0.062 & $1314.7[811.8-1719.5]$ & 700.5 [614.7-1265.3] & 0.113 \\
\hline $24-\mathrm{P}$ & $31[22-35]$ & 15 [14-42] & 0.142 & $873.6[710.3-2074.1]$ & 761.0 [604.4-1203.2] & 0.428 \\
\hline $36-B$ & $43[33-58]$ & $27[15-29]$ & 0.026 * & $1150.8[849.3-1803.8]$ & 846.0 [658.4-1553.2] & 0.383 \\
\hline 36-P & 68 [36-99] & $54[42-111]$ & 0.843 & 856.0 [771.0-1337.8] & 808.9 [631.1-1753.3] & 0.663 \\
\hline 31-B & $25[19-33]$ & $13[6-38]$ & 0.321 & $1404.7[712.3-1846.4]$ & 773.5 [635.4-1696.1] & 0.303 \\
\hline $31-\mathrm{P}$ & $31[23-40]$ & $29[15-33]$ & 0.362 & 1294.9 [765.9-1926.1] & 806.0 [664.9-1178.8] & 0.235 \\
\hline $44-\mathrm{B}$ & $28[18-44]$ & $18[9-31]$ & 0.204 & 1120.8 [666.5-1632.2] & $965.4[560.4-1220.2]$ & 0.267 \\
\hline 44-P & $40[28-51]$ & 23 [9-39] & 0.074 & $1250.9[740.0-1691.5]$ & 900.0 [663.2-1162.9] & 0.154 \\
\hline
\end{tabular}

Legend: B, buccal/labial; P, palatal/lingual; * $p$-value $<0.05$ for the Mann-Whitney test.

Table 4. Results of ROC analysis for gingival crevicular fluid volume.

\begin{tabular}{cccc}
\hline Stimulant & AUC & SE & $p$-Value \\
\hline $16-\mathrm{B}$ & 0.458 & 0.157 & 0.791 \\
$16-\mathrm{P}$ & 0.488 & 0.150 & 0.937 \\
$11-\mathrm{B}$ & 0.357 & 0.134 & 0.287 \\
$11-\mathrm{P}$ & 0.327 & 0.146 & 0.236 \\
$24-\mathrm{B}$ & 0.381 & 0.160 & 0.458 \\
24-P & 0.601 & 0.151 & 0.504 \\
$36-\mathrm{B}$ & 0.685 & 0.151 & 0.221 \\
$36-\mathrm{P}$ & 0.554 & 0.137 & 0.695 \\
$31-\mathrm{B}$ & 0.476 & 0.148 & 0.873 \\
$31-\mathrm{P}$ & 0.500 & 0.151 & $>0.999$ \\
$44-\mathrm{B}$ & 0.530 & 0.161 & 0.854 \\
$44-\mathrm{P}$ & 0.649 & 0.121 & 0.219 \\
\hline
\end{tabular}

Legend: B, buccal/labial; P, palatal/lingual.

Table 5. Results of ROC analysis for interleukin- $1 \beta$ concentration.

\begin{tabular}{cccc}
\hline Stimulant & AUC & SE & $p$-Value \\
\hline $16-B$ & 0.714 & 0.118 & 0.070 \\
$16-P$ & 0.440 & 0.160 & 0.710 \\
$11-B$ & 0.583 & 0.129 & 0.519 \\
$11-P$ & 0.667 & 0.140 & 0.233 \\
$24-B$ & 0.607 & 0.142 & 0.452 \\
$24-P$ & 0.571 & 0.156 & 0.648 \\
$36-B$ & 0.690 & 0.118 & 0.107 \\
$36-P$ & 0.548 & 0.158 & 0.763 \\
$31-B$ & 0.595 & 0.139 & 0.494 \\
$31-P$ & 0.571 & 0.148 & 0.629 \\
$44-B$ & 0.560 & 0.139 & 0.668 \\
$44-P$ & 0.571 & 0.142 & 0.615 \\
\hline
\end{tabular}

Legend: B, buccal/labial; P, palatal/lingual. 


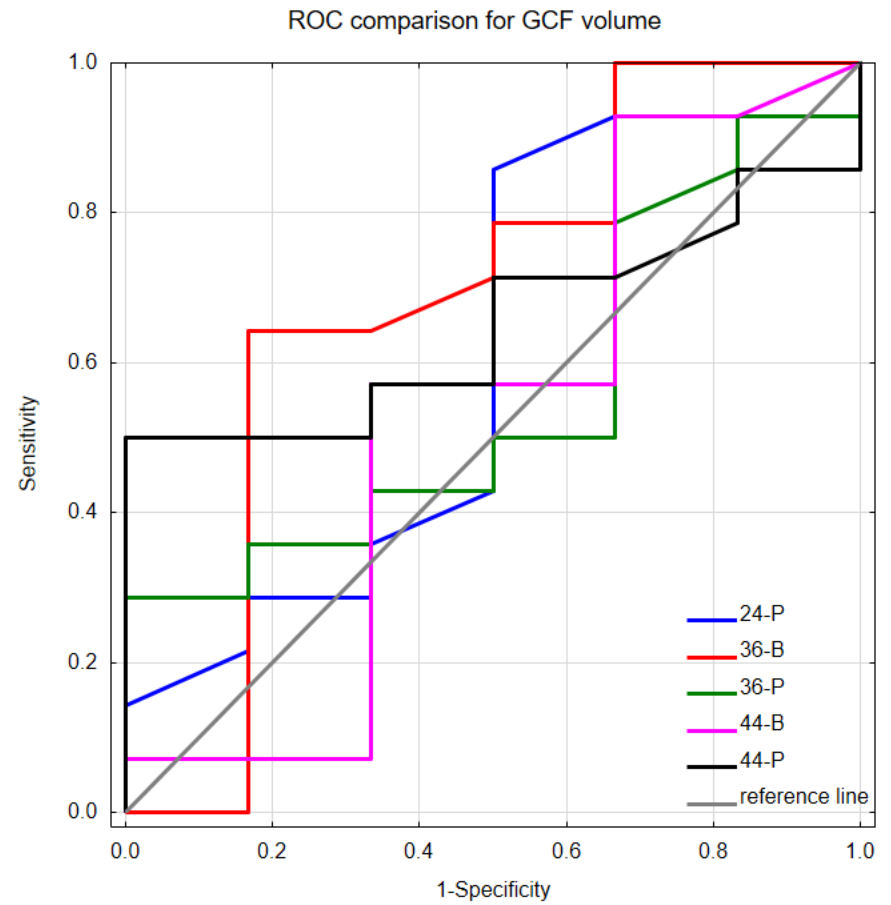

Figure 4. ROC curves for gingival crevicular fluid volume (B, buccal/labial; P, palatal/lingual).

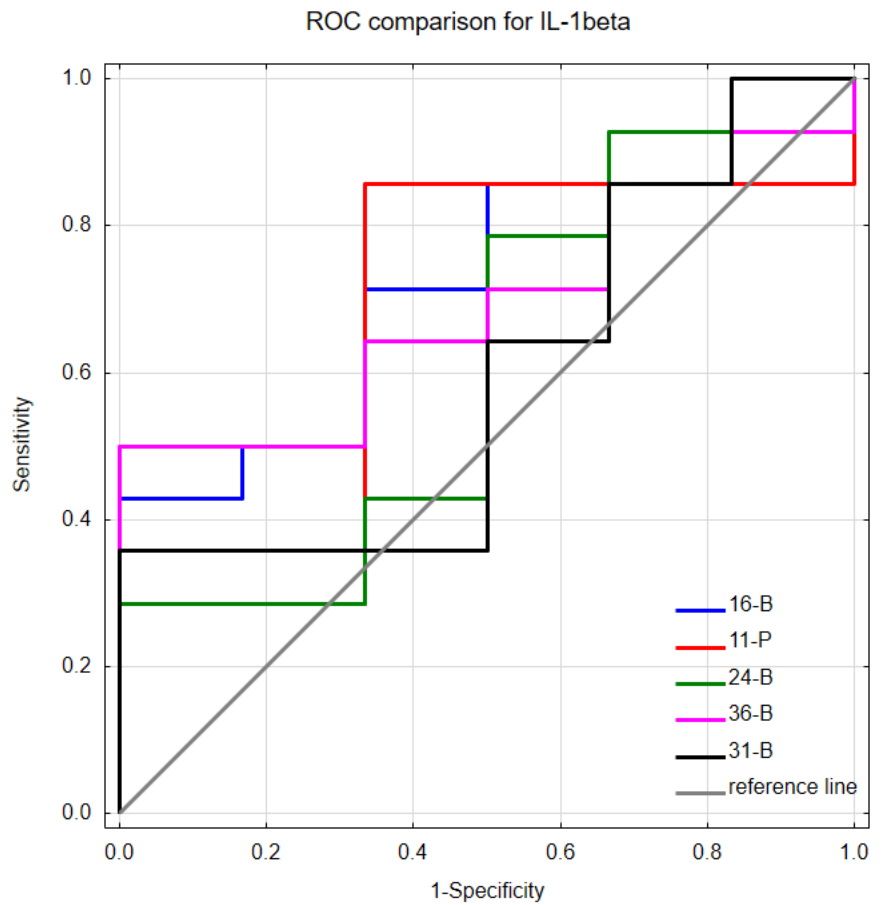

Figure 5. ROC curves for interleukin-1 $\beta$ concentration (B, buccal/labial; $\mathrm{P}$, palatal/lingual).

The most representative gingival crevice that accurately classified bruxists based on the volume of gingival crevicular fluid secreted seemed to be the crevice near the buccal surface of tooth 36 . In contrast, based on IL-1 $\beta$ concentration in GCF, the crevice near the buccal surface of tooth 16 may have the best predictive power, as indicated by the largest AUC in the ROC analysis (close to the statistical significance level). 


\section{Discussion}

In our preliminary study, the greatest upward trend in GCF secretion concerned in premolars and molars, i.e., lateral teeth in the support zones, which may be related to increased occlusal overload in this area due to clenching and grinding. In addition, patients with pathological tooth wear showed a trend toward elevated concentrations of proinflammatory interleukin- $1 \beta$, especially in incisor and premolar teeth. This may indicate an increased susceptibility of bone to remodeling in this area.

The problem of bruxism is beginning to be perceived as a comorbid disease, reflected by the state and condition of the tissues of the entire stomatognathic system. In 2017, Thymi et al. [29] designed a prospective cohort study to answer whether bruxism is a risk factor for peri-implantation complications. On the other hand, peri-implantitis is associated with elevated levels of IL-1 $\beta$ in GCF [30-33].

According to the literature, the issue of the influence of bruxism on the amount and composition of GCF is not popular among researchers. However, there are many reports on the fluctuations in GCF secretion depending on various factors. Urbaniak et al. [15] evaluated GCF secretion depending on the menstrual cycle phase. Women with no signs of periodontitis were qualified for the study. The results indicated that hormonal status changes during the menstrual cycle caused a significant increase in the amount of GCF in the periovulatory phase, but did not lead to clinically visible signs of periodontitis. Moreover, BinShabaib et al. [34] found significantly elevated GCF secretion and concentrations of contained proinflammatory cytokines (IL-1 $\beta$, IL-6, tumour necrosis factor- $\alpha$, matrix metalloproteinase- 8 , and interferon- $\gamma$ ) in cigarette smokers compared to e-cigarette smokers and non-smokers, which correlated with the level of poor periodontal health status in this group. In contrast, Slawik et al. [35] found smaller volumes of GCF secretion and thus less gingival inflammation after the daily consumption of milk containing probiotics, but emphasised its high cariogenic potential due to its high carbohydrate content and Lactobacilli strain.

Orthodontic treatment influence on the composition of GCF is frequently discussed in the literature. Drummond et al. [16] investigated the changes in GCF volume during treatment with a fixed appliance with a titanium-molybdenum arch. A slight but significant increase in GCF volume was observed, which may be a consequence of clinically imperceptible inflammation in periodontal tissues caused by the use of orthodontic forces. The subject of this research is not only the volume, but also changes in the composition of GCF. The concentration of prostaglandin E (PGE) and interleukin- $1 \beta$-mediators of bone resorption-in GCF during orthodontic tooth movement was studied by Grieve et al. [36]. Increased production of PGE and IL- $1 \beta$ in treated teeth was observed in the early stages of therapy. Tzannetou et al. [37] focused on detecting the inflammatory mediators IL-1 $\beta$ and $\beta$-glucuronidase in adolescents who underwent rapid palate expansion using a Hyrax screw. The authors confirmed that orthodontic and orthopaedic movements trigger an aseptic inflammatory process. The increase in IL-1 levels occurred both by direct and indirect applications of mechanical force to the teeth. A similar study concerning the determination of IL-1 $\beta$ concentrations in GCF from the fissure of lower incisal teeth in patients during orthodontic treatments with self-ligating braces was conducted by Kalemaj et al. [38].

Furthermore, Castroflorio et al. [39] analysed the presence of bone metabolism markers (including IL-1 $\beta$ ) during orthodontic treatments with the aligner technique. There was an increased concentration of IL-1 $\beta$ on the side under the influence of orthodontic forces. The available literature suggests that the increase in GCF volume may be a consequence of subclinical inflammation-microinflammation-occurring in periodontal tissues. The authors hypothesised that occlusal overload caused by bruxism, such as orthodontic forces, may affect the volume and composition of GCF, including the concentration of proinflammatory cytokines.

Additionally, a study by Attar et al. [13] showed that as gingival index values and periodontal pocket depth increased, GCF volume increased. Higher volumes were also observed in the direction from incisor teeth $(0.12-0.69 \mu \mathrm{L})$ to molar teeth $(0.24-0.93 \mu \mathrm{L})$, which 
is anatomically related to the increasing gingival crevice area. In contrast, Arif et al. [40] determined a correlation between GCF volume and gingival index values, finding no such relationship with the depth of periodontal pockets at teeth treated with porcelain veneers. Interestingly, Abdullah Al-Abdaly [41] evaluated the effect of chewing khat leaves on GCF secretion among the Yemeni population. An increase in gingival index values and GCF volumes was observed with longer chewing habits, suggesting a higher prevalence of periodontal inflammatory disease. In contrast, plaque index values decreased, which was explained by the ability to self-clean the teeth while chewing these leaves. In other studies, periodontitis markers such as alkaline phosphatase [3] and monocyte chemotactic protein MCP-1 [42] were also determined in GCF.

The Periotron can also be used to assess the amount of GCF secreted in the subclinical inflammation of periodontal tissues. Bevilacqua et al. [43] compared gingival fluid secretion from the fissures around healthy teeth and those with periodontal disease, and around implants and those with visible peri-implantitis. There was no difference between the volumes of fluid produced at teeth and implants in the same state of periodontal tissue health or disease; however, both resulted in higher volumes of fluid when active inflammation was found. A significant correlation between fluid volume and periodontal pocket depth was only obtained for healthy tissue. Analogously, a study by Ata-Ali et al. [44] analysed the relationship between the presence of bacteria (such as Tannerela forsythia, Porphyromonas gingivalis, Treponema denticola, and Aggregatibacter actinomycetemcomitans) and the volume of fluid secreted from the sulcus around the implants. A significant correlation was obtained between the percentage of bacteria present around the implants and the amount of fluid absorbed by soaked Periopaper strips for $30 \mathrm{~s}$. The authors suggest that the determined volume of secreted fluid from the fissure and its correlation with concentrations of red group bacteria may allow the prediction of the occurrence of peri-implantitis.

Researchers are increasingly looking for a relationship between bruxism and periodontal status. As emphasised by Bilgin Çetin et al. [45], the results of previous studies assessing the relationship between bruxism and periodontal disease are contradictory. The mentioned authors in 2021 stated that probable bruxism is related to periodontitis. Among a group of over 500 patients, those who reported grinding and clenching their teeth showed a greater risk of periodontitis. On the other hand, Botelho et al. [46] presented in 2019 the results of a cross-sectional study involving over 1000 respondents, reaching opposite conclusions. Patients who declared tooth grinding showed a lower incidence of periodontitis and better clinical manifestation of the disease. Multivariate analysis performed on the above-mentioned subjects suggested that bruxism is significantly associated with a lower risk of periodontitis.

It should be emphasised that so far, researchers have only evaluated the clinical manifestation of tissues available in a physical examination, using international periodontal status indicators. The performed studies did not include the collection of GCF samples and did not take into account the biochemical assessment of cytokines. As our study suggests, GCF collected from the crevices at molars 16 and 36 may be a reliable indicator of microinflammation in periodontal tissues.

The main limitation of our study seems to be the relatively small sample size, although this was compensated for by the number of GCF samples taken from each patient. Furthermore, making a diagnosis of bruxism as only a "probable" grade without instrumental assessment can be considered a weak point of our pilot. In further studies, detailed evaluation of the occlusal contacts with overload points would be advisable.

\section{Conclusions}

Patients diagnosed with probable bruxism, as a result of occlusal overload, are more prone to microinflammation in periodontal tissues compared to people without visible signs. The measurement of gingival fluid volume and the concentration of interleukin- $1 \beta$ may be reliable predictors for diagnosing periodontal microinflammation due to clenching and grinding of the teeth in patients with probable bruxism. Non-invasive detection of 
potential markers in GCF shows that subclinical periodontitis could allow faster diagnosis and the prevention of further inflammatory processes. In order to confirm the observed dependencies, it is necessary to continue this research on a wider group of patients.

Author Contributions: Conceptualisation, K.N.; methodology, K.N. and A.S.; formal analysis, K.N.; investigation and resources, M.O., A.M., K.N., A.B., and M.N.; writing-original draft preparation, M.O., A.M., and K.N.; writing —review and editing, K.N. and A.S.; visualisation, K.N.; supervision, A.S. and D.F. All authors have read and agreed to the published version of the manuscript.

Funding: This research received no external funding.

Institutional Review Board Statement: The study was conducted according to the guidelines of the Declaration of Helsinki and approved by the Bioethics Committee of the Poznan University of Medical Sciences (171/20-13 February 2020).

Informed Consent Statement: Informed consent was obtained from all subjects involved in the study.

Data Availability Statement: Data are available on request from the corresponding author.

Acknowledgments: The project was implemented with the use of funds for science awarded by the Poznan University of Medical Sciences.

Conflicts of Interest: The authors declare no conflict of interest.

\section{References}

1. Fatima, T.; Khurshid, Z.; Rehman, A.; Imran, E.; Srivastava, K.C.; Shrivastava, D. Gingival Crevicular Fluid (GCF): A Diagnostic Tool for the Detection of Periodontal Health and Diseases. Molecules 2021, 26, 1208. [CrossRef] [PubMed]

2. Gilowski, Ł.; Płocica, I.; Wiench, R.; Kalamarz, I.; Krzemiński, T.F. The Application of Periotron 8000 in Diagnosis and Studies of Periodontal Diseases. Dent. Med. Probl. 2004, 41, 107-111.

3. Perozini, C.; Chibebe, P.C.A.; Leao, M.V.P.; da Silva Queiroz, C.; Pallos, D. Gingival Crevicular Fluid Biochemical Markers in Periodontal Disease: A Cross-Sectional Study. Quintessence Int. 2010, 41, 877-883. [PubMed]

4. Heboyan, A.; Manrikyan, M.; Zafar, M.S.; Rokaya, D.; Nushikyan, R.; Vardanyan, I.; Vardanyan, A.; Khurshid, Z. Bacteriological Evaluation of Gingival Crevicular Fluid in Teeth Restored Using Fixed Dental Prostheses: An In Vivo Study. Int. J. Mol. Sci. 2021, 22, 5463. [CrossRef] [PubMed]

5. De Aguiar, M.C.S.; Perinetti, G.; Capelli, J. The Gingival Crevicular Fluid as a Source of Biomarkers to Enhance Efficiency of Orthodontic and Functional Treatment of Growing Patients. BioMed Res. Int. 2017, 2017, 3257235. [CrossRef] [PubMed]

6. Nijakowski, K.; Surdacka, A. Salivary Biomarkers for Diagnosis of Inflammatory Bowel Diseases: A Systematic Review. Int. J. Mol. Sci. 2020, 21, 7477. [CrossRef] [PubMed]

7. Gamonal, J.; Acevedo, A.; Bascones, A.; Jorge, O.; Silva, A. Levels of Interleukin-1 Beta, -8, and -10 and RANTES in Gingival Crevicular Fluid and Cell Populations in Adult Periodontitis Patients and the Effect of Periodontal Treatment. J. Periodontol. 2000, 71, 1535-1545. [CrossRef]

8. Romano, F.; Del Buono, W.; Bianco, L.; Arena, M.; Mariani, G.M.; Di Scipio, F.; Berta, G.N.; Aimetti, M. Gingival Crevicular Fluid Cytokines in Moderate and Deep Sites of Stage III Periodontitis Patients in Different Rates of Clinical Progression. Biomedicines 2020, 8, 515. [CrossRef]

9. McDevitt, M.J.; Russell, C.M.; Schmid, M.J.; Reinhardt, R.A. Impact of Increased Occlusal Contact, Interleukin-1 Genotype, and Periodontitis Severity on Gingival Crevicular Fluid IL-1beta Levels. J. Periodontol. 2003, 74, 1302-1307. [CrossRef]

10. Da Silva, F.R.P.; Vasconcelos, A.C.C.G.; de Carvalho França, L.F.; Di Lenardo, D.; Nascimento, H.M.S.; Vasconcelos, D.F.P. Association between the Rs1143634 Polymorphism in Interleukin-1B and Chronic Periodontitis: Results from a Meta-Analysis Composed by 54 Case/Control Studies. Gene 2018, 668, 97-106. [CrossRef]

11. Daneshmand, H.; Wade, A.B. Correlation between Gingival Fluid Measurements and Macroscopic and Microscopic Characteristics of Gingival Tissue. J. Periodontal Res. 1976, 11, 35-46. [CrossRef] [PubMed]

12. Hyun, Y.-C.; Lee, Y.-J. Gingival Crevicular Fluid Measure on Individual Tooth by Use of Periotron 8000. Int. J. Clin. Prev. Dent. 2009, 5, 031-037.

13. Attar, N.B.; Banodkar, A.B.; Gaikwad, R.P.; Patil, C.L.; Simon, S. Evaluation of Gingival Crevicular Fluid Volume in Relation to Clinical Periodontal Status with Periotron 8000. Int. J. Appl. Dent. Sci. 2018, 4, 68-71.

14. Nijakowski, K.; Surdacka, A. Diagnostics of Gingival Crevicular Fluid Using the Periotron 8000. In Biofizyka a Medycyna. T. 8.; Wydawnictwo Naukowe Uniwersytetu Medycznego im. K. Marcinkowskiego w Poznaniu: Poznań, Poland, 2019; pp. 170-180.

15. Urbaniak, M.; Wiench, R.; Gilowski, Ł.; Płocica, I.; Krzemiński, T.F. The Amount of Gingival Crevicular Fluid in the Different Phases of the Menstrual Cycle. Dent. Med. Probl. 2012, 49, 523-528.

16. Drummond, S.; Canavarro, C.; Perinetti, G.; Teles, R.; Capelli, J. The Monitoring of Gingival Crevicular Fluid Volume during Orthodontic Treatment: A Longitudinal Randomized Split-Mouth Study. Eur. J. Orthod. 2012, 34, 109-113. [CrossRef] 
17. Lobbezoo, F.; Ahlberg, J.; Raphael, K.G.; Wetselaar, P.; Glaros, A.G.; Kato, T.; Santiago, V.; Winocur, E.; De Laat, A.; De Leeuw, R.; et al. International Consensus on the Assessment of Bruxism: Report of a Work in Progress. J. Oral Rehabil. 2018, 45, 837-844. [CrossRef]

18. Manfredini, D.; Ahlberg, J.; Lobbezoo, F. Bruxism Definition: Past, Present, and Future-What Should a Prosthodontist Know? J. Prosthet. Dent. 2021, in press. [CrossRef]

19. Flueraşu, M.I.; Bocşan, I.C.; Tig, I.-A.; Iacob, S.M.; Popa, D.; Buduru, S. The Epidemiology of Bruxism in Relation to Psychological Factors. Int. J. Environ. Res. Public Health 2022, 19, 691. [CrossRef]

20. Wieckiewicz, M.; Bogunia-Kubik, K.; Mazur, G.; Danel, D.; Smardz, J.; Wojakowska, A.; Poreba, R.; Dratwa, M.; ChaszczewskaMarkowska, M.; Winocur, E.; et al. Genetic Basis of Sleep Bruxism and Sleep Apnea-Response to a Medical Puzzle. Sci. Rep. 2020, 10, 7497. [CrossRef]

21. Maciejewska-Szaniec, Z.; Kaczmarek-Ryś, M.; Hryhorowicz, S.; Przystańska, A.; Gredes, T.; Maciejewska, B.; Hoppe-Gołębiewska, J.; Słomski, R.; Pławski, A.; Czajka-Jakubowska, A. Polymorphic Variants in Genes Related to Stress Coping Are Associated with the Awake Bruxism. BMC Oral Health 2021, 21, 496. [CrossRef]

22. Vavrina, J.; Vavrina, J. Bruxism: Classification, Diagnostics and Treatment. Praxis 2020, 109, 973-978. [CrossRef] [PubMed]

23. Manfredini, D.; Ahlberg, J.; Aarab, G.; Bracci, A.; Durham, J.; Ettlin, D.; Gallo, L.M.; Koutris, M.; Wetselaar, P.; Svensson, P.; et al. Towards a Standardized Tool for the Assessment of Bruxism (STAB)-Overview and General Remarks of a Multidimensional Bruxism Evaluation System. J. Oral Rehabil. 2020, 47, 549-556. [CrossRef] [PubMed]

24. Manfredini, D.; Lobbezoo, F. Sleep Bruxism and Temporomandibular Disorders: A Scoping Review of the Literature. J. Dent. 2021, 111, 103711. [CrossRef] [PubMed]

25. Michalek-Zrabkowska, M.; Wieckiewicz, M.; Smardz, J.; Gac, P.; Poreba, R.; Wojakowska, A.; Mazur, G.; Martynowicz, H. Determination of Inflammatory Markers, Hormonal Disturbances, and Sleepiness Associated with Sleep Bruxism Among Adults. Nat. Sci. Sleep 2020, 12, 969-979. [CrossRef]

26. Michalek-Zrabkowska, M.; Wieckiewicz, M.; Macek, P.; Gac, P.; Smardz, J.; Wojakowska, A.; Poreba, R.; Mazur, G.; Martynowicz, H. The Relationship between Simple Snoring and Sleep Bruxism: A Polysomnographic Study. Int. J. Environ. Res. Public Health 2020, 17, 8960. [CrossRef]

27. Lobbezoo, F.; Ahlberg, J.; Glaros, A.G.; Kato, T.; Koyano, K.; Lavigne, G.J.; de Leeuw, R.; Manfredini, D.; Svensson, P.; Winocur, E. Bruxism Defined and Graded: An International Consensus. J. Oral Rehabil. 2013, 40, 2-4. [CrossRef]

28. Smith, B.G.; Knight, J.K. An Index for Measuring the Wear of Teeth. Br. Dent. J. 1984, 156, 435-438. [CrossRef]

29. Thymi, M.; Visscher, C.M.; Yoshida-Kohno, E.; Crielaard, W.; Wismeijer, D.; Lobbezoo, F. Associations between Sleep Bruxism and (Peri-) Implant Complications: A Prospective Cohort Study. BDJ Open 2017, 3, 17003. [CrossRef]

30. Mohammadi, H.; Roochi, M.M.; Sadeghi, M.; Garajei, A.; Heidar, H.; Meybodi, A.A.; Dallband, M.; Mostafavi, S.; Mostafavi, M.; Salehi, M.; et al. Association between Interleukin-1 Polymorphisms and Susceptibility to Dental Peri-Implant Disease: A Meta-Analysis. Pathogens 2021, 10, 1600. [CrossRef]

31. Alassy, H.; Parachuru, P.; Wolff, L. Peri-Implantitis Diagnosis and Prognosis Using Biomarkers in Peri-Implant Crevicular Fluid: A Narrative Review. Diagnostics 2019, 9, E214. [CrossRef]

32. Nogueira-Filho, G.; Pesun, I.; Isaak-Ploegman, C.; Wijegunasinghe, M.; Wierzbicki, T.; McCulloch, C.A. Longitudinal Comparison of Cytokines in Peri-Implant Fluid and Gingival Crevicular Fluid in Healthy Mouths. J. Periodontol. 2014, 85, 1582-1588. [CrossRef] [PubMed]

33. Yaghobee, S.; Khorsand, A.; Paknejad, M. Comparison of Interleukin-1 $\beta$ Levels in Gingival Crevicular Fluid and Peri-Implant Crevicular Fluid and Its Relationship with Clinical Indexes. J. Dent. 2013, 10, 1-9.

34. BinShabaib, M.; ALHarthi, S.S.; Akram, Z.; Khan, J.; Rahman, I.; Romanos, G.E.; Javed, F. Clinical Periodontal Status and Gingival Crevicular Fluid Cytokine Profile among Cigarette-Smokers, Electronic-Cigarette Users and Never-Smokers. Arch. Oral Biol. 2019, 102, 212-217. [CrossRef] [PubMed]

35. Slawik, S.; Staufenbiel, I.; Schilke, R.; Nicksch, S.; Weinspach, K.; Stiesch, M.; Eberhard, J. Probiotics Affect the Clinical Inflammatory Parameters of Experimental Gingivitis in Humans. Eur. J. Clin. Nutr. 2011, 65, 857-863. [CrossRef]

36. Grieve, W.G.; Johnson, G.K.; Moore, R.N.; Reinhardt, R.A.; DuBois, L.M. Prostaglandin E (PGE) and Interleukin-1 Beta (IL-1 Beta) Levels in Gingival Crevicular Fluid during Human Orthodontic Tooth Movement. Am. J. Orthod. Dentofac. Orthop. Off. Publ. Am. Assoc. Orthod. Const. Soc. Am. Board Orthod. 1994, 105, 369-374. [CrossRef]

37. Tzannetou, S.; Efstratiadis, S.; Nicolay, O.; Grbic, J.; Lamster, I. Comparison of Levels of Inflammatory Mediators IL-1beta and BetaG in Gingival Crevicular Fluid from Molars, Premolars, and Incisors during Rapid Palatal Expansion. Am. J. Orthod. Dentofac. Orthop. Off. Publ. Am. Assoc. Orthod. Const. Soc. Am. Board Orthod. 2008, 133, 699-707. [CrossRef]

38. Kalemaj, Z.; Buti, J.; Deregibus, A.; Canuto, R.M.; Maggiora, M.; Debernardi, C.L. Aligning Effectiveness, Secretion of Interleukin $1 \beta$ and Pain Control During Fixed Orthodontic Treatment with Self-Ligating Appliances and Supplemental Vibrational Appliances. A Randomized Controlled Clinical Trial. J. Biomed. 2017, 2, 25-33. [CrossRef]

39. Castroflorio, T.; Gamerro, E.F.; Caviglia, G.P.; Deregibus, A. Biochemical Markers of Bone Metabolism during Early Orthodontic Tooth Movement with Aligners. Angle Orthod. 2017, 87, 74-81. [CrossRef]

40. Arif, R.; Dennison, J.B.; Garcia, D.; Yaman, P. Gingival Health of Porcelain Laminate Veneered Teeth: A Retrospective Assessment. Oper. Dent. 2019, 44, 452-458. [CrossRef] 
41. Abdullah Al-Abdaly, M.M.A. Evaluation of Gingival Crevicular Fluid Volume by (Periotron 8000) ${ }^{\circledR}$ in Yemeni Qat Chewing Samples. J. Dent. Res. Rev. 2016, 3, 51-53. [CrossRef]

42. Gunpinar, S.; Alptekin, N.O.; Dundar, N. Gingival Crevicular Fluid Levels of Monocyte Chemoattractant Protein-1 in Patients with Aggressive Periodontitis. Oral Dis. 2017, 23, 763-769. [CrossRef] [PubMed]

43. Bevilacqua, L.; De Biasi, M.; Lorenzon, M.G.; Frattini, C.; Angerame, D. Volumetric Analysis of Gingival Crevicular Fluid and Peri-Implant Sulcus Fluid in Healthy and Diseased Sites: A Cross-Sectional Split-Mouth Pilot Study. Open Dent. J. 2016, 10, 131-138. [CrossRef] [PubMed]

44. Ata-Ali, J.; Flichy-Fernandez, A.J.; Alegre-Domingo, T.; Candel-Marti, M.E.; Penarrocha, D.; Balaguer-Martinez, J.; Penarrocha, M.A. Analysis of the Peri-Implant Microbiota in 90 Dental Implants and Its Relationship to Crevicular Fluid Volume. Med. Oral Patol. Oral Cir. Bucal 2011, 16, e944-e947. [CrossRef]

45. Bilgin Çetin, M.; Sezgin, Y.; Maraş, E.; Cebeci, İ.A. Association of Probable Bruxism with Periodontal Status: A Cross-Sectional Study in Patients Seeking Periodontal Care. J. Periodontal Res. 2021, 56, 370-378. [CrossRef] [PubMed]

46. Botelho, J.; Machado, V.; Proença, L.; Rua, J.; Martins, L.; Alves, R.; Cavacas, M.A.; Manfredini, D.; Mendes, J.J. Relationship between Self-Reported Bruxism and Periodontal Status: Findings from a Cross-Sectional Study. J. Periodontol. 2019, 91, 1049-1056. [CrossRef] [PubMed] 